\title{
Spindle Design of Walnut Sheller Giving Clearance and Modal Analysis
}

\author{
Zhang Hong \\ College of Mechanical and Electronic \\ Engineering \\ Tarim University \\ Alar Xinjiang, China \\ 47024899@qq.com \\ Ma Shaohui \\ College of Mechanical and Electronic \\ Engineering \\ Tarim University \\ Alar Xinjiang, China \\ ngynj@sina.com
}

\author{
Hao Zhongcheng \\ College of Mechanical and Electronic \\ Engineering \\ Tarim University \\ Alar Xinjiang, China \\ 243252568@qq.com \\ Zhang Rui \\ CollegeofLifeScienc \\ Tarim University \\ Alar Xinjiang, China \\ 843037930@qq.com
}

\begin{abstract}
Based on the spindle design walnut sheller clearance and the walnut shell breaking force analysis, taking into account the discontinuity in the work spindle, configurations, factors such as speed and material, creating a dynamic model optimized using finite element analysis. The results shows that reducing the natural frequency of the shaft, selecting the appropriate bearing and symmetrical design, can effectively improve the sheller spindle life and improve shelling efficiency.
\end{abstract}

Keywords-Principal axis; giving clearance; Modal Analysis; nut-cracking; walnut shelling

\section{INTRODUCTION}

In order to realize walnut food added value, many countries are working to find ways to manufacture shelled walnuts. Currently prices of whole shelled walnut prices in the international market is several times the price of unshelled walnuts, and stored unshelled walnuts rot easily. Using walnut shelling equipment improves processing efficiency for walnut processing companies, reduces manual labor intensity, but also created employment opportunities for the community. Particularly in the walnut orchard areas, walnut processing can became a pillar industry in the local economy. Research and design of a high efficiency, good reliability walnut sheller can solve business bottlenecks.

Abroad development of walnut shelling equipment designs started earlier, the shelling technology is basically mature. The main walnut shelling machine designs are:

JEAN-PIERRE LACOMBE developed application No. FR9009864A walnut shelling machine. The machine relies on the motor and the conveyor to achieve the synchronous rotation of the upper and lower shaft, and rely on the solenoid valve to achieve synchronous movement of the conveyor and small cylinder that fixed on the flange that installed in the vertical axis. The machine has compact structure, high efficiency broken shell, walnut breakage rate characteristics.

(2) VAN RIPER CLIFF developed Publication No. US4246699 walnut shell broken machine. The aircraft is the use of complement each other of spiral grind barrel and roll to achieve a broken walnut shells. The machine 
has a very high efficiency broken shell, walnut low breakage rate characteristics.

(3) MTCHEDLIDZE VAKHTAN developed Publication No. KR20097000061 walnut shell broken machine. The machine use walnuts clamping device, the device hit the spindle drive sprocket driven together with the spindle rotation to form a multi-position pneumatic walnut shell broken machine. The machine has the characteristics of transport can be achieved, positioning, walnut grip, broken shells and unloading of synchronization operations.

The domestic developed shelling machines relative to foreign walnut shelling designs is slow, lagging far behind the demand for agricultural products. Local designed walnut shelling equipment is inefficient, high losses, shelled walnut integrity is poor and has higher operating costs as the outstanding problems. The main machinery for walnut shelling:

Shi Jianxin, Dong Shihan to develop a walnut sheller[1]. The design uses the compression and shear effects on walnut as relative motion of dynamic cone and fixed cone to crack walnuts. The machine has a simple structure.

Li ZhongXin, Yang Jun, MaiHe Mujiang develop of a walnut shelling machine. The machine works by rotating the turntable to break the shell of the walnut strike impact. The machine has the characteristics of high shelling efficiency.

Li Zhangtai invented an automatic walnut sheller; the machine breaks the shell by squeezing the head that can intermittent lift, with a high degree of automation, high efficiency broken shell, and low walnut breakage rate characteristics.

Zhong Xin, Han Xiaojun, Qi Xinzhou et al developed the flat extrusion walnut shelling machine. Through an active and a passive plate rolling motion it achieves the cracking and removing of the walnut shells. The machine is safe, reliable and convenient.

\section{SPINDLE DESIGN WALNUT SHELLER}

The spindle design with given clearance walnut shelling machine is compact, allows processing without prior classification and results in a good shelling effect[2]. The principal axis is the key component, when operating it is subject to dynamic loads; the speed requirement is 800 rev/min. Therefore, the design process must account of the force of the spindle, the balance and rolling friction problem. The structure is shown in Fig. 1:

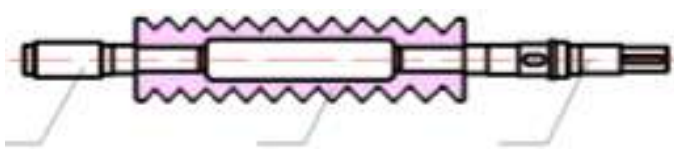

Figure 1. 1Axis1

2.Squeeze rollers

\section{Axis 2}

Structure Principal axis

Shaft 1 , shaft 3 and and the pressing roller are tight fit. right pulley shaft 3, by V-belt tension, The second keyway with gear, is passed to the next squeeze roller shaft to form a relatively extrusion. Squeeze roller cavity structure is designed to reduce the weight of the design. To avoid producing larger imbalance dynamic loads While rotating selection of interference fit. As the shaft is the key component to break walnut shells, forces generated when broken walnut shells have a certain impact on the double roll gap[3]. While the pair of rolls during the rotation, will have a certain dynamic load this will affect the gap between the two rolls. Ultimately this has an impact on the quality of the walnut shelling. Plus the force of the shaft relative to the complex, the more complicated the structure, hence the need to analyze its dynamics. Since the axis is greater interference fit when analyzed by whole treat analysis[4].

\section{PHYSICAL MODEL SPINDLE AND MODAL ANALYSIS}

\section{A. The Reason Vibration Generated When the Work}

The reason walnut shell breaking machine spindle work vibrate when there is a lot, not only the amount of unbalance caused by factors such design processing and assembly, there are many other factors. Through on-site analysis of the walnut sheller, summed up the vibration of their work time The main reasons are as follows[5]:

(1) Walnut sheller when broken shell,its high-speed rotation of the spindle receives impact from walnut, thereby adding an exciting force to the spindle, the spindle will vibrate.

(2) By a walnut sheller spindle structure shows that when the bearing long working hours due to wear and tear create gap reduce radial bearing preload and swivel accuracy This makes walnut sheller vibration will 
increase significantly after long-term work.

(3) Walnut sheller spindle driven by a pulley, belt of pulley tensioner force causes shaft bending and deformation. Axle at high speeds, and bending of the shaft will cause vibration.

\section{B. Dynamic Modeling[6]}

Before performing kinetic analysis, need to establish a computational model. Is to abstract the actual rotating machinery, Get a can reflect the dynamic characteristics of the original rotating machinery, And mechanical systems suitable for computational analysis of a reasonable calculation model, consider the following three aspects:

(1) Response of the structure and operation of the actual machinery;

(2) a clear mechanical problems to be analyzed, For example, the rotor is bending vibration, or torsional vibration, is seeking natural frequency, or the analysis of stability;

(3) to adapt the existing calculation methods and tools. To facilitate the calculations, we break the shell machine spindle static characteristics as the spatial elastic beam to deal with, what is more detailed spindle unit simplified.

(1) The left end of the spindle axis and the intersection of the axis of the bearing as a fixed end, the right end of the spindle at the intersection of the axis of the shaft and the bearing in the axial direction considered swimming end;

(2) The spindle simplified rigid support, ignoring elasticity affect the bearing.

According to the simplification principle, the establishment features analysis model[7] shown in Fig. 2.

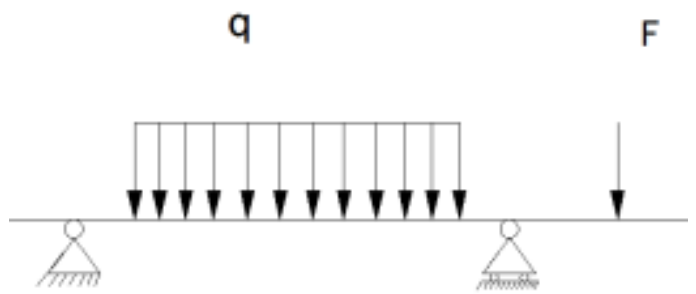

Figure 2. spindle force model diagram

\section{Selection of Unit Type and Mesh [8]}

The selection of 10-node model SOLID92 three-dimensional solid element type, mesh on the spindle. After selecting the unit, broken shell of machine spindle meshing of this analysis, finite element mesh model results shown in Fig. 3 there were 46,086 units of the model, the number of nodes is 69948 .

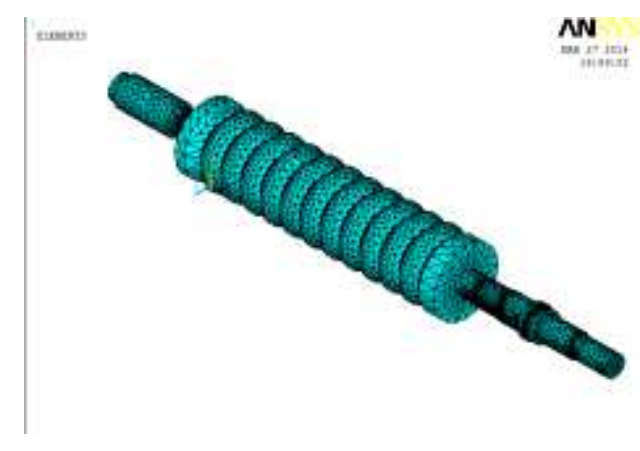

Figure 3. mesh

\section{Spindle Static Deformation Finite Element Calculations}

Fig. 5 shows the model is applied to the bearings of the spindle constraints, according to known extrusion pressure and tension pulley walnuts, ANSYS stress diagram the calculation of the output shaft of the diagram and the static deformation of the spindle[9], as shown in Fig. 4 and Fig. 5 .

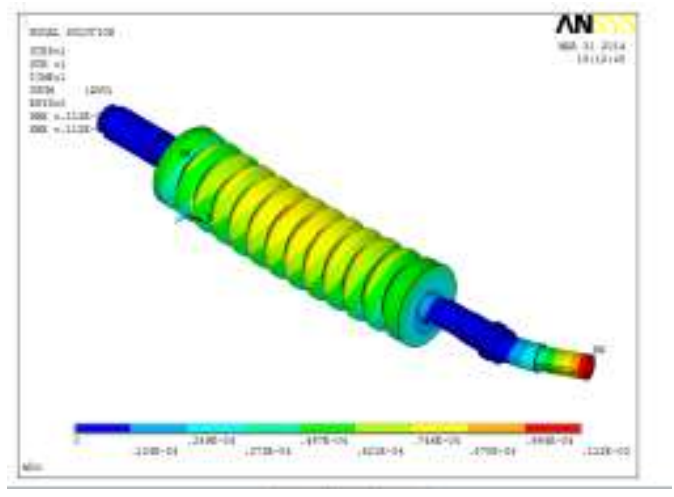

Figure 4. spindle static deformation maps

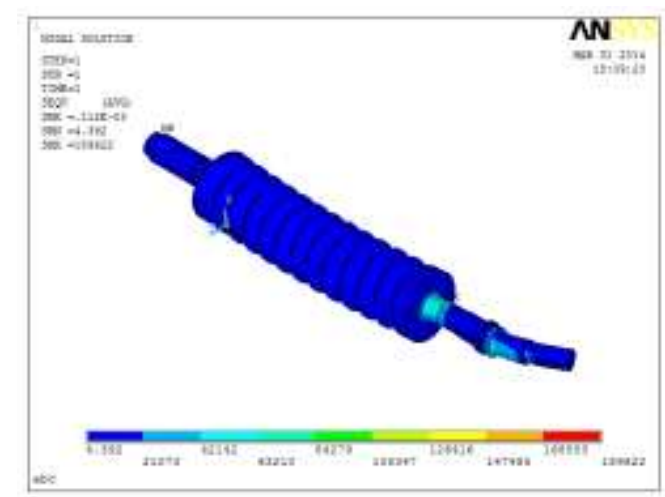

Figure 5. spindle stress 
As can be seen from the above two plans, the spindle pulley end displacement $\mathrm{DMX}=112 \mathrm{um}$, the spindle stiffness[10]:

$\mathrm{K}=\frac{\mathrm{F}}{\mathrm{DMX}}=\frac{1920}{112}=17.14 \mathrm{~N} / \mathrm{um}$

The spindle design requirements, requirements for static stiffness is $230 \mathrm{~N} / \mathrm{um}$, apparently, the spindle designed to meet the requirements of static stiffness.

\section{CONCLUSION}

Through the finite element analysis of static characteristics of the spindle, the following points are given major measures to improve the dynamic characteristics of the spindle:

Reduce the natural frequency of the shaft: bending and rocking spindle system, the right end of the spindle bearings. Therefore, the focus is on the right processing equipment bearing end. The most effective method is to increase the stiffness and damping of the shaft assembly, the bearing preload and stiffness of the bearing on its maximum load.

(2) Select the appropriate bearing: Bearing selection principle is to maximize the former shorten spindle overhang.

(3) Improve the dynamic performance of spindle: best use of symmetrical design, and reduce the spindle coupling, the best way is through the ANSYS optimization tool spindle system optimization.

\section{ACKNOWLEDGMENT}

This project is financially supported by National natural science foundation of the People's Republic of China (31160196,31260469), Xinjiang Production and Construction Corps technology industry research projects (2014BA014)

\section{REFERENCES}

[1] Shi Jianxin, Xin Dongjun. Domestic walnut shell breaking the status quo and take Jen mechanical Discussion [J]. Xinjiang Agricultural Mechanization, 2001 (06) :29-32.

[2] Shi Jianxin, Zhao Haijun, Xin Dongjun. Technology for breaking walnut shell based on finite element analysis [J]. Transactions of the CSAE, 2004, 19(4): 9-12. (in Chinese with English abstract)

[3] Zhang Hong.Reflection on Mechaniztion of Walnut Production in Xinjiang[J].Forestry machinery\&woodworking equipment. 2011,39(2):13-14 (in Chinese with English abstract)
[4] Wu ziyue.Research on Principle and Mechanics of Cracking and Extracting Kernel of Soft-walnut [J]. Transactions of the CSAE, 1995, 11(12): 64-69. (in Chinese with English abstract)

[5] Zeng Pan.finite element analysis and application [J] Beijing: Tsinghua University Press, 2004:. 249-297 (7 - 9 literature magazine omitted)

[6] Fan Zhengang, Li Qiang. dynamics simulation [J] Based on ANSYS and ADAMS engine crankshaft. Machinery manufacturing and automation, 2007,36 (3) :89-91.

[7] Wu Qingxi. Theoretical Mechanics [M] Beijing: Higher Education Press, 2003.

[8] Zhang Chaohui.ANSYS12.0 resolve structural analysis engineering application [M] Beijing: Mechanical Industry Press, 2010.

[9] Li Shi.stepped shaft Finite Element Analysis and Optimization of professional software development [D] Changsha: Hunan University, 2008.

[10] Zhang Hong, Zhang Peng. European wooden windows dedicated push Taiwan milling spindle design method [J]. Forestry practical technology, (2010) 06:64-65. 